\title{
Serious Myasthenia at the Department of Internal Medicine of Point G University Teaching Hospital: A Clinical Case
}

\author{
Assétou Kaya Soukho ${ }^{1}$, Djenebou Traoré1, Adramé Keita1, Djibril Sy1, Guida Landouré2, \\ Seybou Hassane Diallo ${ }^{3}$, Youssouf Fofana4, Kaly Keita1, Mamadou Mallé1, Ibrahima Amadou \\ Dembélé1, Drissa Sangaré1, Mamadou Cissoko , Barry Boubacar Sangarée, Mamadou Dembélé1, \\ Abdel Kader Traoré ${ }^{1}$, Hamar Alassane Traoré ${ }^{1}$
}

\footnotetext{
${ }^{1}$ Department of Internal Medicine, Point G University Teaching Hospital, Bamako, Mali

${ }^{2}$ Department of Neurology, Point G University Teaching Hospital, Bamako, Mali

${ }^{3}$ Department of Neurology, GABRIEL TOURE University Teaching Hospital, Bamako, Mali

${ }^{4}$ Department of Internal Medicine, Mother-Child Hospital "Luxembourg”, Bamako, Mali

Email: *assetousouko@yahoo.fr
}

How to cite this paper: Soukho, A.K., Traoré, D., Keita, A., Sy, D., Landouré, G., Diallo, S.H., Fofana, Y., Keita, K., Mallé, M., Dembélé, I.A., Sangaré, D., Cissoko, M., Sangaré, B.B., Dembélé, M., Traoré, A.K. and Traoré, H.A. (2019) Serious Myasthenia at the Department of Internal Medicine of Point G University Teaching Hospital: A Clinical Case. Neuroscience \& Medicine, 10, 207-212.

https://doi.org/10.4236/nm.2019.103015

Received: July 21, 2019

Accepted: September 3, 2019

Published: September 6, 2019

Copyright $\odot 2019$ by author(s) and Scientific Research Publishing Inc. This work is licensed under the Creative Commons Attribution International License (CC BY 4.0).

http://creativecommons.org/licenses/by/4.0/

\begin{abstract}
Introduction: Myasthenia is a rare and disabling autoimmune disease. Few studies were devoted to this pathology. We report a clinical case of myasthenia in the Department of Internal Medicine at the Point G University Teaching Hospital. Observation: This is a 41-year-old patient of Malian origin, a trader with a history of hemorrhoidectomy in 2011 and familial hypertension, was admitted on August 19, 2014, for muscle weakness, dysphonia, and dysphagia. The disease started 1 year before admission at the department with progressive muscle weakness of the upper limbs aggravated by repetitive movements and spreading to the head "drooping head" and inferior limbs, associated with general fatigue, dysphonia and selective dysphagia for solid foods. The diagnosis of myasthenia was maintained based on the clinical signs such as ptosis, bilateral diplopia, and weakness with lower limbs muscle strength rated at $3 / 5$, and confirmed with confirmatory exams; a positive anti-acetylcholine receptor antibody (RIA), the post-synaptic neuromuscular conduction block at ENMG and the positive neostigmine pharmacological test. The patient received Neostigmine (prostagmine) $0.5 \mathrm{mg}$ one ampoule in IM/day and Prednisone at a dosage of 1 $\mathrm{mg} / \mathrm{kg} /$ day. The evolution was marked by a moderate improvement of the symptomatology afterward the patient was evacuated to Tunisia on family request where he received a course of immunoglobulin $2 \mathrm{~g} / \mathrm{kg}$ in 2 days. The evolution in Tunisia was favorable. The patient returned in Mali and death occurred after 2 months in a context of respiratory distress. Conclusion: Myasthenia is a rare but serious disease requiring careful management and monitor-
\end{abstract}


ing to reduce respiratory complications.

\section{Keywwords}

Myasthenia, Immunoglobulin, Internal Medicine, Point G Hospital

\section{Introduction}

Myasthenia is a chronic and disabling autoimmune disease which lesion is located between the nerve and the muscle, at the neuromuscular junction level [1], affecting the somatic nervous system and therefore only the striated muscles [2]. It is a rare disease, according to current estimates in North America, the prevalence of serious myasthenia (SM) is about 19 to 21 per 100,000 populations [3]. In South Africa, the prevalence of SM was 10.42 cases per 100,000 people in 2010 , increasing annually to reach 12.99 cases per 100,000 people in 2014. In Mali, there were 9 cases of serious myasthenia over 5 years from 2011 to 2016, of which the age range of 20 - 40 years represented $77.79 \%$ according to Sacko report [4]. We report a case of myasthenia in a 41-year-old patient in the Department of Internal Medicine at Point G University Teaching Hospital. No cases had been diagnosed in our department. The description of this case will allow us to list these rare pathologies to have a database.

\section{Observation}

A 41-year-old patient, Malian origin, trader, with a history of hémorroïdectomy in 2011 and familial hypertension, was admitted on August 19, 2014 for muscle weakness, dysphonia and dysphagia at the Department of Internal Medicine of the University Teaching Hospital of Point G. The disease started 1 year before admission to the department, marked by progressive installation of upper limbs muscle weakness aggravated by repetitive movements and spreading to the head "drooping head" and inferior limbs, associated with general fatigue, dysphonia and selective dysphagia for solid foods.

The persistence of these symptoms and the association with respiratory distress mainly asphyxia, the patient has performed several traditional medicines in bathing and orally without clinical improvement.

The patient weighed $62 \mathrm{~kg}$ for a height of $1.70 \mathrm{~cm}$ with a Body Mass Index of $21.45 \mathrm{~kg} / \mathrm{m}^{2}$.

His temperature was $37.4^{\circ} \mathrm{C}$; his blood pressure was normal with $120 / 80 \mathrm{~mm}$ $\mathrm{Hg}$. The respiratory rate was $19 \mathrm{cycles} / \mathrm{min}$ and the heart rate was 120 beats $/ \mathrm{min}$.

The consciousness was conserved with a Glasgow at 15/15. Upper limbs muscle strength rated at $4 / 5$ and lower limb muscle strength rated $3 / 5$. There was good tonicity. Ptosis and bilateral binocular diplopia were revealed by cranial pairs' examination. The footstool sign was present.

The initial hemogram showed a hemoglobin normal level at $15.9 \mathrm{~g} / \mathrm{dl}$, hematocrit was normal at $45.9 \%$, mean globular volume (MGV) was normal at $79.6 \mathrm{fl}$, 
normal serum creatinine level at $82 \mathrm{umol} / \mathrm{l}$, normal blood glucose at $4.8 \mathrm{mmol} / \mathrm{l}$, normal Transaminases (ALAT $=25,9 \mathrm{IU} / \mathrm{L}, \mathrm{AST} / \mathrm{GOT}=23.2 \mathrm{IU} / \mathrm{L}$ )

The dosage of THSus was normal with $1.25 \mathrm{mU} / \mathrm{L}$. Phosphokinase creatine (PKC) level was high with $1319 \mathrm{IU} / \mathrm{L}$. The antibody anti-nuclear was negative with $0.62 \mathrm{EU}$. The C-reactive protein (CRP) was $68.1 \mathrm{mg} / \mathrm{l}$. The dosage of the anti-acetylcholine receptor (RIA) antibody showed a high level at $47.50 \mathrm{nmol} / \mathrm{l}$. The pharmacological test in neostigmine was positive. The post-synaptic neuromuscular conduction block (serious myasthenia) was found at Electroneuromyogram (ENMG). The chest CT scan performed was normal (Figure 1).

The tachycardia associated with the footstool sign was present. The hypothesis of hyperthyroidism was mentioned. The dosage of TSHus was normal.

The dermatopolymyositis was suspected based on the association of muscular weakness with dysphonia, dysphagia, ptosis and the footstool sign. The PKC was high; the dosage of the antinuclear antibody was negative. The Myogenic syndrome was not found at EMG. The muscle biopsy was not performed.

The diagnosis of myasthenia was retained based on the positive neostigmine therapeutic test, positive anti-acetylcholine receptor antibody (RIA) and the postsynaptic neuromuscular conduction block found at ENMG.

The patient received Neostigmine (prostagmine) at a dose of $0.5 \mathrm{mg} 1 \mathrm{am}$ poule in IM/day and Prednisolone $20 \mathrm{mg}$ at a dose of $1 \mathrm{mg} / \mathrm{kg} / \mathrm{day}$ equivalent to 3 pills/day per os in decreasing dosage associated with adjuvant measures (chloride of potassium $600 \mathrm{mg}$, a capsule/day Calcium $1 \mathrm{~g}: 1$ pill/day and Ivermectin 3 $\mathrm{mg}$ at the dosage of $200 \mu \mathrm{g} / \mathrm{kg} /$ day for two days, and Immunoglobulin in IV 2 $\mathrm{g} / \mathrm{kg}$ in 2 days.

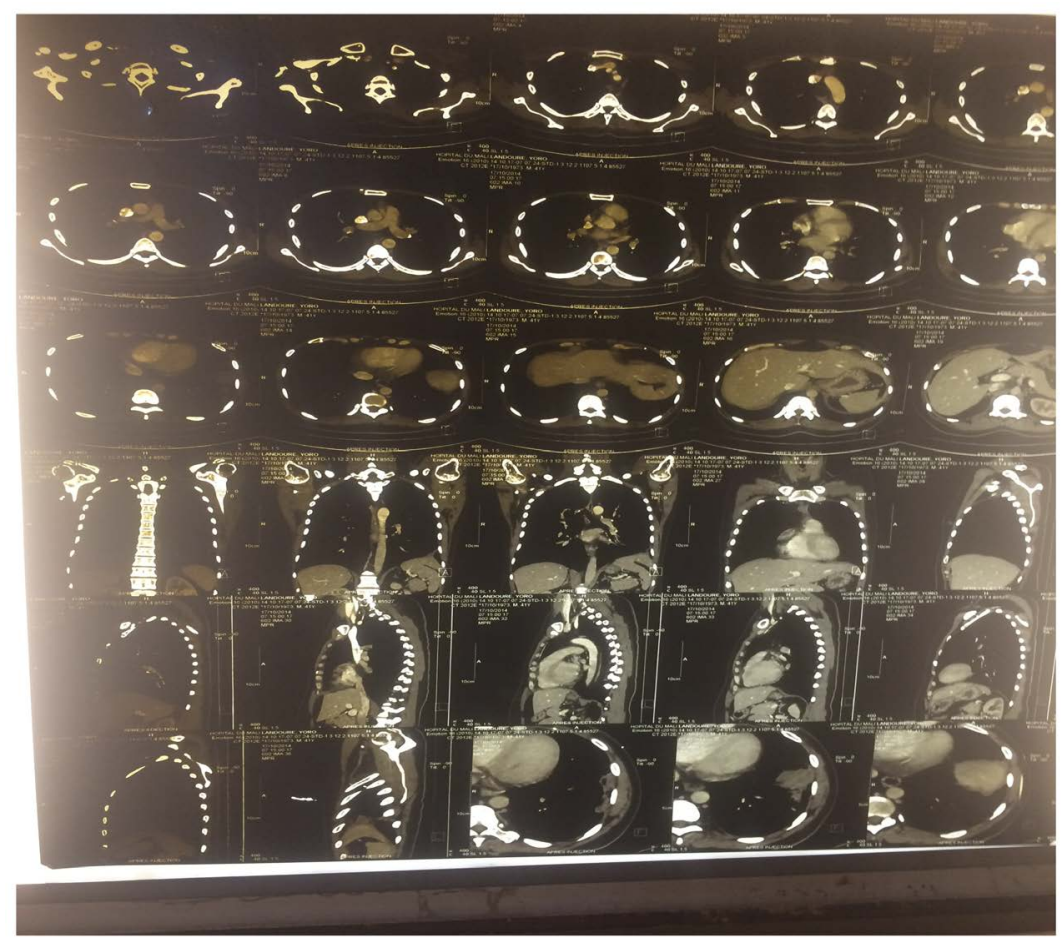

Figure 1. Chest CT scan: normal. 
The evolution was marked by a moderate improvement of the symptomatology afterward the patient was evacuated in Tunisia at the request of the family where he received a course of immunoglobulin with $2 \mathrm{~g} / \mathrm{kg}$ in 2 days. The evolution in Tunisia was favorable.

After return to Mali, death occurred 2 months later in a context of respiratory distress.

\section{Discussion}

Myasthenia is an autoimmune pathology of the neuromuscular junction, clinically characterized by the installation of fluctuating muscle weakness with, in its classical form, symptoms limited to ptosis and diplopia [5].

Its incidence varies from $1.7-10.4$ per million per year to 21 per million in Barcelona. Its prevalence increases according to the latest statistics. It is observed at any age with two peaks:

- The first peak between 20 - 40 years old where women are more affected;

- The second peak after 50 years where men are the most affected [6].

Its prevalence, unknown in France, is estimated in the literature from 100 to 200 per million [7]. Our patient was 41 , age under 50 years which constitutes a particularity.

The reason for consulting of our patient was dysphonia and dysphagia. These signs are found in $5 \%$ of the cases whereas the muscular weakness was found in $10 \%$ of cases according to Grob et al. [8]. In another study, dysphagia was present in $37 \%$ of patients and dysphonia in $34 \%$ of patients. Signs as bilateral binocular diplopia were found in $79 \% \mathrm{~s} \%$ of cases [9] and the ptosis in $5 \%$ of cases [8].

The diagnosis of myasthenia in our patient was based on the positive neostigmine therapeutic test, which has a sensitivity of less than $100 \%$ [10]. The anti-acetylcholine receptor antibody was positive at $47.50 \mathrm{nmol} / \mathrm{l}$ for our patient. In one study, anti-acetylcholine receptor antibody was found in $94 \%$ of patients with asthenia and in $71 \%$ of patients with ocular myasthenia [11] and $80 \%$ to $90 \%$ of generalized myasthenia [12]. The postsynaptic neuromuscular conduction block was found at ENMG (electroneuromyogram), this neuromuscular block with electromyogram is greater than $80 \%$ for pure ocular forms and $95 \%$ for generalized forms [13].

Our patient received Neostigmine (prostagmine) at a dose of $0.5 \mathrm{mg}$ with 1 ampoule in IM/day causing regression of the symptomatology. In a recent study of 34 patients aged over 65 years, cholinesterase inhibitors (Neostigmine) only were sufficient for $41 \%$ of them [12]. In another study, the initial response to anticholinesterase treatment was fine (R, RP, AM) in 15 cases (54 p. 100) according to a comparative study of myasthenia in youth in two groups of subjects at different age all having myasthenia.

Prednisone $20 \mathrm{mg}$ at a dosage of $1 \mathrm{mg} / \mathrm{kg} /$ day corresponding to $3 \mathrm{cp} /$ day in a decreasing dose had led to an improvement in clinical signs. This effectiveness of 
corticotherapy was better in patients over 40 years old or having started their myasthenia after 40 years [9].

In a series of 116 patients treated with $1 \mathrm{mg} / \mathrm{kg}$ per day of prednisone, only $14 \%$ of patients were able to discontinue corticosteroids for their side effects (Pascuzzi et al., 1984).

The use of Immunoglobulin IV at a dose of $2 \mathrm{~g} / \mathrm{kg}$ for two days had been effective. In the study conducted by Gajdos et al. (2005), the percentage of responders to IV Immunoglobulin was $50 \%$ to $60 \%$ [14].

Improvement percentages of up to $75 \%$ have been reported for both therapies in several series analyzed retrospectively [15] [16].

Assessing evolution, our patient had an improvement both clinically and paraclinical marked by a decrease in muscle weakness, progressive disappearance of dysphonia and dysphagia.

Clinical evolution is marked by the transitory regression, more or less complete of signs according to Goulon-Goeau C [17].

\section{Conclusions}

Autoimmune myasthenia is a rare disease with eye manifestations mostly inaugural directing the subject towards to the ophthalmologist. It is the first diagnosis to suspect in front of bilateral ptosis or not, fluctuating or not, and muscular weaknesses and dysphonia. Early diagnosis and neurological management would limit the risk of generalization of the disease that can compromise the vital prognosis. No treatment can definitely cure myasthenia.

Studies are needed to determine the possible particularities of the disease in sub-Saharan Africa given its scarcity.

\section{Conflicts of Interest}

The authors declare no conflicts of interest regarding the publication of this paper.

\section{References}

[1] Meriggioli, M.N. and Sanders, D.B. (2005) Advances in the Diagnosis of Neuromuscular Junction Disorders. American Journal of Physical Medicine \& Rehabilitation, 84, 627-638. https://doi.org/10.1097/01.phm.0000171169.79816.4c

[2] Mekrani, S. and Brignol, T.N. (2006) Autoimmune Myasthenia 10/2006.

[3] Hyung, S.L., Hye, S.L., et al. (2016) The Epidemiology of Myasthenia Gravis in Korea, Departments of Neurology and Biostatistics, Yonsei University College of Medicine, Seoul, Korea. Yonsei Medical Journal, 57, 419-425.

https://doi.org/10.3349/ymj.2016.57.2.419

[4] Sacko, M. (2016) Clinical, Paraclinical, and Therapeutic Aspects of Autoimmune Myasthenia Gravis in the Neurology Department of the Point G University Teaching Hospital. Thesis.

[5] Erkan, D., Cervera, R. and Asherson, R.A. (2003) Catastrophic Antiphospholipid Syndrome: Where Do We Stand? Arthritis \& Rheumatology, 48, 3320-3327. https://doi.org/10.1002/art.11359 
[6] Juel, V.C. and Massey, J.M. (2007) Myasthenia Gravis. Orphanet Journal of Rare Disease, 2, 44. https://doi.org/10.1186/1750-1172-2-44

[7] Eymard, B. (2014) Myasthenia on the Side of the Internist. La Revue de Médecine Interne, 35, 421-429. https://doi.org/10.1016/j.revmed.2013.08.013

[8] Grob, D., Arsura, E.L., Brunner, G. and Namba, T. (1987) The Race of Myasthenia Gravis and Therapies Affecting the Outcome. Annals of the New York Academy of Science, 505, 472-499. https://doi.org/10.1111/j.1749-6632.1987.tb51317.x

[9] Barbaud, A., et al. (2006) Late Forms of Myasthenia; Comparative Study with Myasthenia of the Young Subject. Revista de Neurología, 162, 990-996. https://doi.org/10.1016/S0035-3787(06)75109-8

[10] Linda, R., et al. (2017) Autoimmune Myasthenia Jacks-Up and Therapeutic Management of the Pharmacy; Memory Ended Studies to Obtain the Diplomas of Doctor of Pharmacy, 05/15/2017, Algeria.

[11] Gajdos, P. (2004) Myasthenia Seronegative. Revista de Neurología, 160, 159-162. https://doi.org/10.1016/S0035-3787(04)70886-3

[12] Saraux-Bonneton, A., et al. (2001) D'une observation; Département de gériatrie, hôpital Vaugirard-Gabriel-Pallez. Revista de Internal, 22, 984-987.

[13] Dechy, H., Wechsler, B., Hausfater, P., et al. (2017) Neurological Disorders in Systemic Diseases. 72-77.

[14] Hall-Besnier, D. (2010) Traitement de la myasthénie auto-immune; Département de neurologie, Centre de référence pour les maladies neuromusculaires, Hôpital Universitaire d'Angers. Revista de Neurología, 166, 400-405.

[15] Seybold, M.E. (1987) Plasmapheresis in Myasthenia Gravis. Annals of the New York Academy of Sciences, 505, 584-587.

https://doi.org/10.1111/j.1749-6632.1987.tb51326.x

[16] Van der Meche, F.G. and Van Dorn, P.A. (1997) The Current Place of High Dose Immunoglobulin in the Treatment of Neuromuscular Disorders. Muscle \& Nerve, 20, 136-147. https://doi.org/10.1002/(SICI)1097-4598(199702)20:2<136::AID-MUS1>3.0.CO;2-D

[17] Goblin, C. and Gajdos, P. (2002) Myasthenia and Myasthenic Syndromes. Encyclical Med Chir, Editions Scientifiques et Medicales Elsevier SAS, Paris, Neurology, 17-172-B-10, 14 p. 